\title{
Diaphragmatic parameters by ultrasonography for predicting weaning outcomes
}

\author{
Pongdhep Theerawit ${ }^{1}$, Dararat Eksombatchai ${ }^{2}$, Yuda Sutherasan ${ }^{2 *}$, Thitiporn Suwatanapongched ${ }^{3}$, \\ Charn Kiatboonsri ${ }^{2}$ and Sumalee Kiatboonsri ${ }^{2}$
}

\begin{abstract}
Background: Diaphragmatic dysfunction remains the main cause of weaning difficulty or failure. Ultrasonographic measurement of diaphragmatic function can be used to predict the outcomes of weaning from mechanical ventilation. Our primary objective was to investigate the performance of various sonographic parameters of diaphragmatic function for predicting the success of weaning from mechanical ventilation.

Methods: We prospectively enrolled 68 adult patients requiring mechanical ventilation who were admitted to the intensive care unit from June 2013 to November 2013. The diaphragmatic inspiratory excursion, time to peak inspiratory amplitude of the diaphragm (TPIA dia), diaphragmatic thickness (DT), DT difference (DTD), and diaphragm thickening fraction (TFdi) were determined by bedside ultrasonography performed at the end of a spontaneous breathing trial. A receiver operating characteristic curve was used for analysis.
\end{abstract}

Results: In total, 62 patients were analyzed. The mean TPIA dia was significantly higher in the weaning success group (right, $1.27 \pm 0.38 \mathrm{~s}$; left, $1.14 \pm 0.37 \mathrm{~s}$ ) than in the weaning failure group (right, $0.97 \pm 0.43 \mathrm{~s}$; left, $0.85 \pm 0$. 39 s) $(P<0.05)$. The sensitivity, specificity, positive predictive value, and negative predictive value of a TPIA dia of $>0.8 \mathrm{~s}$ in predicting weaning success were $92,46,89$, and $56 \%$, respectively. The diaphragmatic inspiratory excursion, DTD, and TFdi were associated with reintubation within $48 \mathrm{~h}$. The $P$ values were $0.047,0.021$, and 0 . 028, and the areas under the receiver operating characteristic curve were $0.716,0.805$, and 0.784 , respectively.

Conclusion: Among diaphragmatic parameters, TPIA dia exhibits good performance in predicting the success of weaning from mechanical ventilation. This study demonstrated a trend toward successful use of TPIA dia rather than diaphragmatic inspiratory excursion as a predictor of weaning from mechanical ventilation.

Keywords: Diaphragm ultrasound, Weaning, Spontaneous breathing trial, Diaphragmatic weakness, Diaphragmatic dysfunction

\section{Background}

Diaphragmatic dysfunction remains the main cause of weaning difficulty or failure. Its prevalence ranges from 33 to $95 \%$ [1-5]. Diaphragmatic dysfunction among patients hospitalized in the intensive care unit (ICU) is commonly attributed to critical illness polyneuropathy and myopathy [6]. Mechanical ventilation, even after a

\footnotetext{
* Correspondence: sutherasan_yuda@yahoo.com

2Division of Pulmonary and Pulmonary Critical Care Medicine, Department of Medicine, Faculty of Medicine Ramathibodi Hospital, Mahidol University, Bangkok, 270 Rama 6 Road, Thung Phaya Thai, Ratchathewi, Bangkok 10400, Thailand

Full list of author information is available at the end of the article
}

short period of time, can also induce diaphragmatic dysfunction by reducing the force that generates the capacity of the diaphragm, which may cause weaning difficulty. Diaphragmatic dysfunction can be worsened by disuse atrophy of both fast-twitch and slow-twitch myofibers of the diaphragm following the administration of a neuromuscular blocking agent [7-9].

Several parameters, including the rapid shallow breathing index (RSBI), vital capacity (VC), and maximum peak inspiratory pressure $\left(\mathrm{PI}_{\mathrm{MAX}}\right)$, are routinely used to predict weaning failure from mechanical ventilation. However, the sensitivity, specificity, positive predictive value (PPV),

C The Author(s). 2018 Open Access This article is distributed under the terms of the Creative Commons Attribution 4.0 International License (http://creativecommons.org/licenses/by/4.0/), which permits unrestricted use, distribution, and reproduction in any medium, provided you give appropriate credit to the original author(s) and the source, provide a link to the Creative Commons license, and indicate if changes were made. The Creative Commons Public Domain Dedication waiver (http://creativecommons.org/publicdomain/zero/1.0/) applies to the data made available in this article, unless otherwise stated. 
negative predictive value (NPV), and cut-off values of these parameters are highly variable among studies. Moreover, these parameters do not directly reflect diaphragmatic function [10].

Although fluoroscopic examination of the diaphragm remains the gold standard for evaluation of diaphragmatic movement, it cannot be performed in patients in the ICU. Bedside ultrasound is being increasingly performed for real-time assessment of diaphragmatic movement. This technique allows qualitative and quantitative assessment of diaphragmatic function in terms of diaphragmatic thickness (DT) and diaphragmatic amplitude during contraction, which help to diagnose diaphragmatic weakness [11-14] and respiratory workload [12, 15] in patients in the ICU. Kim et al. [16] found that diaphragmatic excursion of $<10 \mathrm{~mm}$ or paradoxical movement is associated with weaning failure. DiNino et al. [17] suggested that diaphragm contractile function at the zone of apposition as measured by ultrasound may be useful for predicting extubation success or failure. Spadaro et al. [18] recently reported a new index, namely the diaphragmatic RSBI, which is calculated by substituting the tidal volume (TV) with the ultrasonographic evaluation of diaphragmatic displacement. This parameter is more accurate than the traditional RSBI for prediction of weaning failure [18].

To the best of our knowledge, quantitative assessment of both the right and left hemidiaphragms and comparison of these ultrasound parameters with conventional parameters have not been performed. We hypothesized that diaphragmatic parameters determined by bedside ultrasonography can predict the weaning outcome with better performance than conventional parameters. Therefore, we conducted this prospective study to investigate diaphragmatic function in patients in the ICU in terms of diaphragmatic motion and contractile function using bedside ultrasonography during the weaning period. We also evaluated the performance of these ultrasound parameters by comparison with conventional parameters routinely used to predict successful weaning from mechanical ventilation.

\section{Methods}

\section{Study design and patient population}

This prospective cross-sectional study was conducted at a tertiary-care, university-based hospital. The study was approved by the Ethical Clearance Committee on Human Rights Related to Research Involving Human Subjects, Faculty of Medicine Ramathibodi Hospital, Mahidol University (No. MURA2013/414/ $\mathrm{N}_{3} \mathrm{SEP}_{17}$ ).

We consecutively enrolled adult patients aged $>18$ years who were admitted to the medical or surgical ICU of Ramathibodi Hospital, Mahidol University from June 2013 to November 2013. All patients provided written informed consent prior to enrollment. When the patient was unable to provide consent because of consciousness disturbance, the next of kin provided written informed consent.

\section{Inclusion and exclusion criteria}

The inclusion criteria were as follows: 1) a requirement for intubation; 2) readiness for weaning from mechanical ventilation as defined by recovery from the cause of respiratory failure, a stable hemodynamic status, no requirement for a vasopressor, and no administration of sedative agents or neuromuscular blocking agents $>24 \mathrm{~h}$ before enrollment; and 3) readiness for respiration with a T-piece system.

The exclusion criteria were the presence of pneumothorax or ascites, a history of either neuromuscular disease or thoracic surgery, the presence of a tracheostomy tube, and poor image quality. The following baseline characteristics were recorded: age, sex, duration of mechanical ventilation, cause of respiratory failure, body mass index, and laboratory findings before extubation.

\section{Measurements}

In our units, there is no specific (written) criteria by which to determine the best time to start weaning and no formal guidelines for reducing support. In the present study, the patients' readiness to wean was assessed daily by clinical judgment of the attending intensivist and/or pulmonary physician. The primary physicians were blinded to the ultrasound results. The research team did not play a role in deciding whether a patient was to be extubated.

Exhaled TV, RSBI, VC, $\mathrm{PI}_{\mathrm{MAX}}$, and diaphragmatic parameters were measured in all participants at the end of a 2-h spontaneous breathing trial with a T-piece and zero pressure support (before extubation). We employed a hand-held Wright respirometer (Ferraris Medical Ltd., Hertford, Hertfordshire, England) to measure minute ventilation (MV). TV was calculated as MV divided by respiratory rate. The RSBI was the ratio between the respiratory rate (breaths/min) and TV (liters) [19]. Measurement of $\mathrm{VC}$ (slow $\mathrm{VC}$ ) was performed in the upright position, after measurement of MV. During measurement of $\mathrm{VC}$, each patient breathed until the end of inspiration, then exhaled to the approximate residual volume. This process was supervised by a pulmonary fellow. $\mathrm{PI}_{\mathrm{MAX}}$ was measured with a negative inspiratory force meter, which is a calibrated device containing a unidirectional valve, attached to the end of an endotracheal tube (Instrumentation Industries, Inc., Bethel Park, PA, USA). $\mathrm{PI}_{\text {MAX }}$ was determined from the most negative pressure documented during $20 \mathrm{~s}$ of airway occlusion [19]. 
Transthoracic ultrasonography was performed at the bedside with a SonoSite M-Turbo (SonoSite Inc., Bothell, WA, USA) by a well-trained pulmonary physician. The examination was performed in both $\mathrm{B}$ - and anatomical M-modes. All examinations were carried out with patients in the supine position. We obtained diaphragmatic ultrasound values from three consecutive tidal breaths, and the average values were used for analysis.

The diaphragmatic inspiratory excursion and time to peak inspiratory amplitude of the diaphragm $\left(\right.$ TPIA $\left._{\text {dia }}\right)$ of each hemidiaphragm (right TPIA dia and left TPIA dia ) were measured in M-mode using a 1 - to $5-\mathrm{MHz}$ ultrasound transducer during tidal breathing (Fig. 1) [20]. The measurement was performed via either a subcostal or intercostal approach in the mid-clavicular line, or in the right or left anterior axillary line. The liver or spleen was identified as a window for each hemidiaphragm. The ultrasound probe was placed in the direction in which the ultrasound beam reached the posterior third of the corresponding hemidiaphragm perpendicularly [15]. During inspiration, the normal diaphragm moved caudally toward the ultrasound transducer, which was recorded as an upward motion of the M-mode tracing. The amplitude of diaphragmatic inspiratory excursion was measured as the point of maximal height of inspiration in the M-mode tracing. The TPIA $\mathrm{dia}_{\text {a }}$ was defined as the time from the beginning of diaphragmatic contraction to the maximal amplitude of diaphragmatic inspiratory excursion as measured from the M-mode tracing.

DT was subsequently measured at the zone of apposition [15], which is the area of the diaphragm attached

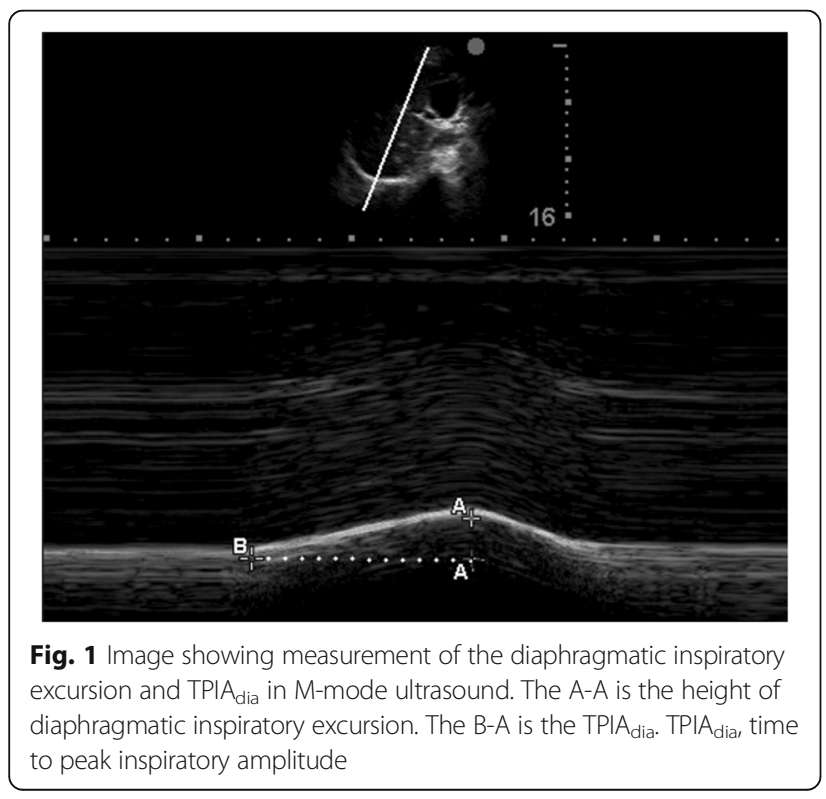

to the rib cage, at both end inspiration and end expiration using a 6-13 ultrasound transducer in $\mathrm{M}$ mode (Fig. 2). The DT difference (DTD) was calculated by subtracting DT at end expiration from DT at end inspiration. The diaphragm thickening fraction (TFdi) was calculated as follows: (DTD)/(DT at end expiration) $\times 100$ [21]. These data were not communicated to the patient care team during the study; they were stored on the hard disk of the ultrasound machine and later exported to files for further verification and analysis. All images were reviewed in terms of image quality by a pulmonary physician and a radiologist (P.T. and T.S.).

\section{Outcomes}

The primary outcome was the diagnostic accuracy of diaphragmatic ultrasound parameters for predicting weaning success. Successful weaning from mechanical ventilation was defined as the ability to tolerate spontaneous breathing for at least $48 \mathrm{~h}$ without any level of assisted ventilation. Weaning failure was defined as the requirement for resumption of either invasive or noninvasive mechanical ventilation or reintubation within $48 \mathrm{~h}$ after extubation [16].

The secondary outcomes were the association between weaning parameters and diaphragmatic dysfunction [16], reintubation during admission, and reintubation within $48 \mathrm{~h}$ after extubation. Ultrasonographic diaphragmatic dysfunction was considered when each hemidiaphragm exhibited either vertical excursion of $<10 \mathrm{~mm}$ or the presence of paradoxical movement [16].

\section{Statistical analysis}

The patients were classified into two groups based on the primary outcome. All parameters were compared between the two groups. The unpaired Student's t-test was used to compare continuous variables, and the chisquare test was used to compare categorical variables. Data are presented as mean \pm standard deviation for continuous variables with a normal distribution and as

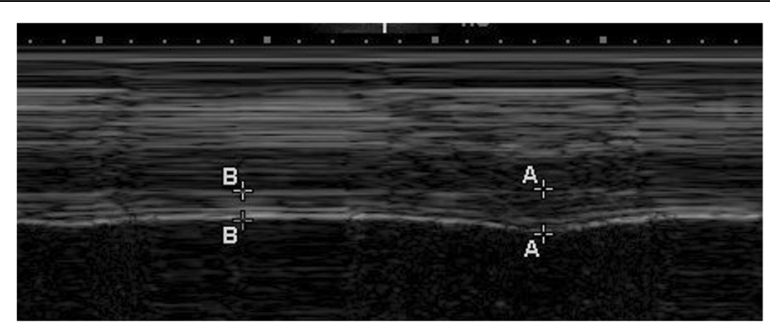

Fig. 2 Image illustrating the part of the diaphragm at the area of apposition for measurement of the diaphragmatic thickness (DT). The A-A is the DT at end inspiration, and the B-B is the DT at end expiration 
median with interquartile range for variables without a normal distribution.

The variables associated with the primary and secondary outcomes were then analyzed with receiver operating characteristic (ROC) curves to determine their performance. Sensitivity and specificity were also analyzed to determine appropriate cut-off values of TPIA $\mathrm{dia}_{\text {a }}$ and RSBI.

To determine the correlation between diaphragmatic ultrasound values and weaning parameters, we used Pearson's correlation and presented the results as correlation coefficients. A $P$ value of $<0.05$ was considered statistically significant. Correlation coefficients of 0.00 to $0.19,0.20$ to $0.39,0.40$ to $0.59,0.60$ to 0.79 , and 0.80 to 1.00 were considered to indicate very weak, weak, moderate, strong, and very strong correlations, respectively. We also performed subgroup analysis between patients with and without diaphragmatic dysfunction.

We analyzed inter-operator variability and intra-operator reproducibility of all diaphragmatic ultrasound parameters in 10 cases by two independent operators who were blinded. The former analysis was performed by Pearson's correlation, and the other was performed with intraclass correlations presented with the correlation coefficient, $P$ value, and 95\% confidence interval. All statistical analyses were performed using IBM SPSS Statistics for Windows, version 22.0 (IBM Corp., Armonk, NY, USA).

\section{Results}

In total, 68 patients were enrolled in our study. In six (9\%) patients, however, the examination was not possible or was limited, resulting in poor image quality. These patients were finally excluded. The images of 62 patients were approved for analysis on the basis of quality. The numbers of patients with weaning success and reintubation are shown in Fig. 3. The patients' baseline characteristics are shown in Table 1. All diaphragmatic parameters obtained from the right and left hemidiaphragm were compared (Table 2), and no difference between the right and

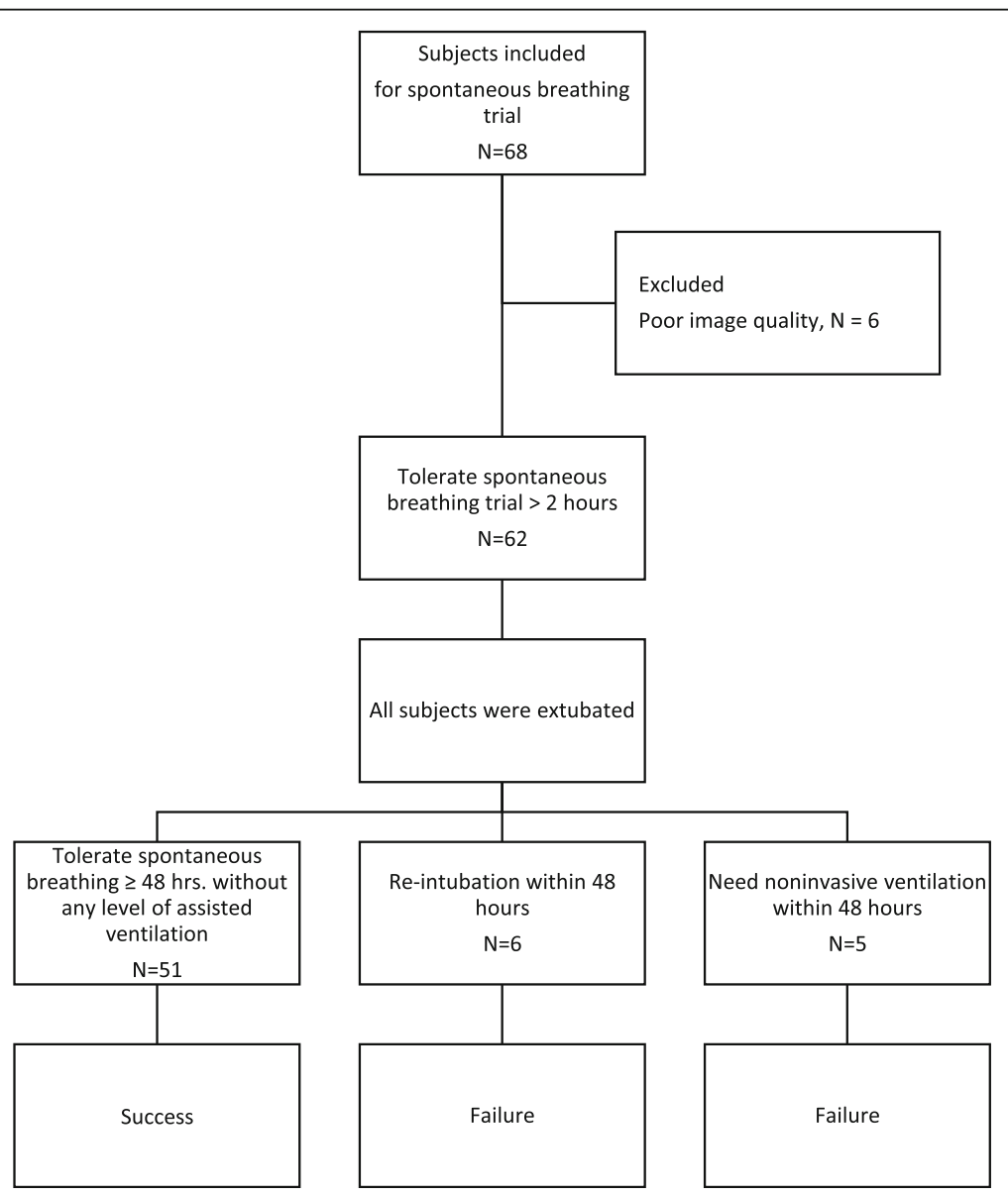

Fig. 3 Flow chart showing the number of patients with weaning success, weaning failure, and reintubation 
Table 1 baseline characteristics

\begin{tabular}{|c|c|}
\hline Demographic data & Value \\
\hline Age (mean $\pm S D$, years) & $66.48 \pm 16.7$ \\
\hline Genders Male (n/\%) & $38 / 61$ \\
\hline Body mass index $\left(\right.$ mean $\left.\pm \mathrm{SD}, \mathrm{kg} / \mathrm{m}^{2}\right)$ & $22.5 \pm 6.3$ \\
\hline Medical patients (n/\%) & $42 / 68$ \\
\hline Surgical patients (n/\%) & $20 / 32$ \\
\hline APACHE II score (mean \pm SD) & $18.5 \pm 7.2$ \\
\hline \multicolumn{2}{|l|}{ Comorbidity (n/\%) } \\
\hline Hypertension & $35 / 57$ \\
\hline Diabetes & $21 / 34$ \\
\hline Chronic kidney disease & $18 / 29$ \\
\hline Ischemic heart disease & $14 / 23$ \\
\hline COPD & $6 / 10$ \\
\hline Hypothyroid & $5 / 8$ \\
\hline Adrenal insufficiency & $3 / 5$ \\
\hline Asthma & $2 / 3$ \\
\hline \multicolumn{2}{|l|}{ Reason for intubation (n/\%) } \\
\hline Neurological disease & $10 / 16$ \\
\hline Septic shock & $10 / 16$ \\
\hline Pneumonia & $8 / 13$ \\
\hline Heart disease & $8 / 13$ \\
\hline COPD exacerbation & $4 / 7$ \\
\hline Post-operative conditions & $21 / 34$ \\
\hline \multicolumn{2}{|l|}{ Laboratory findings (mean $\pm S D$ ) } \\
\hline Sodium (mmol/L) & $135.9 \pm 5.2$ \\
\hline Potassium (mmol/L) & $3.9 \pm 0.59$ \\
\hline Bicarbonate (mmol/L) & $23.6 \pm 4.5$ \\
\hline Calcium (mmol/L) & $7.9 \pm 0.65$ \\
\hline Magnesium (mmol/L) & $1.97 \pm 0.37$ \\
\hline Phosphate (mmol/L) & $4.6 \pm 5.4$ \\
\hline Albumin (g/dl) & $24.8 \pm 5.6$ \\
\hline BUN (mg/dl) & $29.3 \pm 23.9$ \\
\hline Creatinine (mg/dl) & $1.9 \pm 2.3$ \\
\hline Hematocrit (\%) & $31.8 \pm 5.5$ \\
\hline Vital capacity (mean $\pm S D, L)$ & $0.97 \pm 0.4$ \\
\hline Tidal volume (mean $\pm \mathrm{SD}, \mathrm{L})$ & $0.41 \pm 0.2$ \\
\hline $\mathrm{Pl}_{\text {MAX }}($ mean $\pm \mathrm{SD}, \mathrm{mmHg})$ & $40.7 \pm 16.4$ \\
\hline RSBI $\left(\right.$ mean $\pm S D$, breath $\left.\cdot \mathrm{min}^{-1} / \mathrm{L}\right)$ & $60.2 \pm 33.1$ \\
\hline Duration of mechanical ventilation(days) ${ }^{a}$ & $2.8(1.1-5.7)$ \\
\hline \multicolumn{2}{|l|}{ Length of stay (days) } \\
\hline Intensive care stay ${ }^{a}$ & $4.8(2.9-9.6)$ \\
\hline Hospital stay ${ }^{a}$ & $13.3(7.8-25.9)$ \\
\hline
\end{tabular}

APACHE II Acute Physiology and Chronic Health Evaluation II, COPD chronic obstructive airway disease, $B U N$ blood urea nitrogen, $P I_{\text {MAX }}$ Maximum peak inspiratory pressure, $R S B I$ Rapid shallow breathing index

a present as median (inter quartile range)
Table 2 comparison between right and left diaphragmatic parameters

\begin{tabular}{llll}
\hline Ultrasonographic parameters & Right & Left & $P$ value \\
\hline $\begin{array}{l}\text { Diaphragmatic inspiratory } \\
\text { excursion (mm.) }\end{array}$ & $13.5 \pm 6.5$ & $13.4 \pm 6.2$ & 0.87 \\
TPIA $_{\text {dia }}$ (second) & $1.2 \pm 0.40$ & $1.1 \pm 0.39$ & 0.08 \\
Inspiratory DT (mm.) & $3.8 \pm 1.0$ & $3.8 \pm 1.0$ & 0.33 \\
Expiratory DT (mm.) & $2.8 \pm 0.7$ & $2.8 \pm 0.6$ & 0.52 \\
DTD (mm.) & $9.8 \pm 4.9$ & $10.1 \pm 5.1$ & 0.51 \\
TFdi (\%) & $36 \pm 17$ & $35 \pm 14$ & 0.89
\end{tabular}

$T P I A_{\text {dia }}$ Time to peak inspiratory amplitude of diaphragm, $D T$ diaphragmatic thickness, DTD Diaphragmatic thickness difference, TFdi diaphragm thickening fraction

All data are present as mean \pm SD

left diaphragmatic parameters was seen. Consequently, we presented the ultrasound parameters according to the right hemidiaphragm.

With the exception of the potassium level, the demographic factors and laboratory findings did not differ significantly between the weaning success and failure groups (Table 3 ). The mean TPIA $_{\text {dia }}$ was significantly higher in the weaning success than failure group $(P$ $<0.05)$. The RSBI during the spontaneous breathing trial was significantly lower in the weaning success than failure group $(P<0.01)$ (Table 3$)$.

Table 4 shows the correlation coefficients between diaphragmatic and conventional parameters. The TPIA was significantly correlated with TV and inversely correlated with the RSBI (Fig. 4). There were moderate correlations between TPIA dia $_{\text {and }}$ VC, diaphragmatic inspiratory excursion and RSBI, and diaphragmatic inspiratory excursion and TV. The RSBI was inversely related to all diaphragmatic ultrasound parameters. For example, the

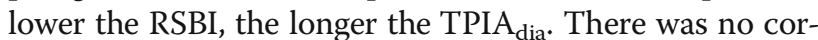
relation between $\mathrm{PI}_{\mathrm{MAX}}$ and any diaphragmatic ultrasound parameters.

Table 5 summarizes the sensitivity, specificity, PPV, and NPV of a TPIA dia of $>0.8 \mathrm{~s}$ and an RSBI of $<100$ in predicting weaning success.

Regarding secondary outcomes, diaphragmatic inspiratory excursion, DTD, and TFdi were significantly lower in patients who underwent reintubation within $48 \mathrm{~h}$. The $P$ values were $0.047,0.021$, and 0.028 , and the areas under the ROC curves were 0.716, 0.805, and 0.784, respectively. A diaphragmatic inspiratory excursion cut-off value of $12.85 \mathrm{~mm}$ provided a sensitivity of $83 \%$ and specificity of $55 \%$ for predicting reintubation within $48 \mathrm{~h}$. The PPV and NPV of a diaphragmatic inspiratory excursion value of $<12.85 \mathrm{~mm}$ were 17 and $97 \%$, respectively. A DTD of $<0.65 \mathrm{~mm}$ predicted reintubation within $48 \mathrm{~h}$ with a sensitivity and specificity of 83 and $77 \%$, respectively. The PPV of a DTD of $<0.65 \mathrm{~mm}$ was $28 \%$, and the NPV was $98 \%$. 
Table 3 comparison between success group and failure group

\begin{tabular}{|c|c|c|c|c|}
\hline Parameters & Weaning success $(n=51)$ & Weaning Failure $(n=11)$ & $P$ value & $95 \% \mathrm{Cl}$ \\
\hline Age (mean $\pm S D$, years) & $65.90 \pm 17.05$ & $69.18 \pm 15.45$ & NS & -7.89 to 14.45 \\
\hline \multicolumn{5}{|l|}{ Gender (n/\%) } \\
\hline Female & $33 / 65$ & $5 / 45$ & & \\
\hline Male & $18 / 35$ & $6 / 55$ & NS & \\
\hline BMI (mean $\left.\pm S D, k g / m^{2}\right)$ & $22.63 \pm 6.18$ & $21.91 \pm 7.66$ & NS & -5.60 to 4.18 \\
\hline APACHE II score & $18.29 \pm 7.88$ & $19.55 \pm 2.34$ & NS & -3.58 to 6.08 \\
\hline \multicolumn{5}{|l|}{ Reason for intubation (n/\%) } \\
\hline Neurological disease & 8/15.7 & $2 / 18.2$ & 0.838 & 0.22 to 6.59 \\
\hline Septic shock & 8/15.7 & $2 / 18.2$ & 0.838 & 0.22 to 6.59 \\
\hline Pneumonia & $6 / 11.8$ & $2 / 18.2$ & 0.623 & 0.29 to 9.62 \\
\hline Heart disease & $6 / 11.8$ & $2 / 18.2$ & 0.623 & 0.29 to 9.62 \\
\hline COPD exacerbation & $3 / 5.9$ & $1 / 9.1$ & 0.694 & 0.15 to 17.00 \\
\hline Post-operative conditions & $19 / 37.3$ & $2 / 18.2$ & 0.305 & 0.07 to 1.92 \\
\hline TV (mean $\pm S D, m l)$. & $420.10 \pm 207.48$ & $370.91 \pm 137.38$ & NS & -82.17 to 180.55 \\
\hline VC (mean $\pm S D, L)$. & $1.01 \pm 0.44$ & $0.76 \pm 0.34$ & NS & -0.05 to 0.54 \\
\hline $\mathrm{RSBI}$ & $55.11 \pm 25.02$ & $83.84 \pm 53.11$ & $P<0.01$ & -49.67 to -7.79 \\
\hline $\mathrm{Pl}_{\mathrm{MAX}}($ mean $\pm \mathrm{SD}, \mathrm{mmHg})$ & $42.31 \pm 17.17$ & $32.50 \pm 8.05$ & NS & -1.34 to 20.97 \\
\hline \multicolumn{5}{|l|}{ Electrolytes (mean \pm SD) } \\
\hline Sodium (mmol/L) & $135.86 \pm 5.03$ & $136.00 \pm 6.21$ & NS & -3.63 to 3.35 \\
\hline Potassium (mmol/L) & $4.00 \pm 0.57$ & $3.46 \pm 0.47$ & $P<0.01$ & 0.17 to 0.92 \\
\hline Bicarbonate $(\mathrm{mmol} / \mathrm{L})$ & $23.54 \pm 4.63$ & $23.81 \pm 4.11$ & NS & -3.29 to 2.75 \\
\hline Magnesium (mmol/L) & $1.97 \pm 0.37$ & $1.99 \pm 0.43$ & NS & -0.32 to 0.28 \\
\hline Phosphate (mmol/L) & $4.92 \pm 5.82$ & $3.01 \pm 0.56$ & NS & -2.58 to 6.38 \\
\hline Calcium (mmol/L) & $7.88 \pm 0.63$ & $8.06 \pm 0.83$ & NS & -0.72 to 0.37 \\
\hline Albumin $(\mathrm{g} / \mathrm{dl})$ & $25.29 \pm 5.34$ & $21.79 \pm 6.26$ & NS & -0.72 to 7.72 \\
\hline Hematocrit (\%) & $32 \pm 6$ & $31 \pm 4$ & NS & -4.79 to 2.58 \\
\hline \multicolumn{5}{|c|}{ Diaphragmatic inspiratory excursion (mean $\pm \mathrm{SD}, \mathrm{mm}$.) } \\
\hline Right & $13.7 \pm 5.6$ & $12.4 \pm 10.0$ & NS & -0.31 to 0.56 \\
\hline Left & $13.5 \pm 5.3$ & $12.8 \pm 09.6$ & NS & -0.35 to 0.48 \\
\hline \multicolumn{5}{|l|}{$\mathrm{TPIA}_{\text {dia }}($ mean $\pm \mathrm{SD}$, second.) } \\
\hline Right & $1.27 \pm 0.38$ & $0.97 \pm 0.43$ & $P<0.05$ & 0.04 to 0.56 \\
\hline Left & $1.14 \pm 0.37$ & $0.85 \pm 0.39$ & $P<0.05$ & 0.04 to 0.54 \\
\hline \multicolumn{5}{|l|}{ DTD $($ mean \pm SD, mm.) } \\
\hline Right & $1.01 \pm 0.46$ & $0.84 \pm 0.66$ & NS & -1.61 to 5.00 \\
\hline Left & $1.05 \pm 0.50$ & $0.80 \pm 0.48$ & NS & -0.84 to 5.82 \\
\hline \multicolumn{5}{|l|}{ TFdi (mean $\pm S D, \%)$} \\
\hline Right & $36 \pm 15$ & $33 \pm 24$ & NS & -15.05 to 7.37 \\
\hline Left & $37 \pm 14$ & $28 \pm 13$ & NS & -18.16 to 0.65 \\
\hline
\end{tabular}

COPD chronic obstructive airway disease, APACHE II acute physiology and chronic health evaluation II, TV Tidal volume, VC vital capacity, RSBI rapid shallow breathing index, $P I_{\text {MAX }}$ Maximum peak inspiratory pressure, TPIA dia time to peak inspiratory amplitude, DTD diaphragmatic thickness difference, TFdi diaphragm thickening fraction

Nineteen of 62 (31\%) patients had diaphragmatic dysfunction according to the criteria established by Kim et al. [16]. Patients who developed diaphragmatic dysfunction had a significantly higher RSBI and lower

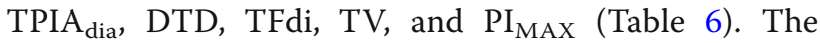
areas under the ROC curves of RSBI, TPIA $A_{\text {dia }}$, DTD, 
Table 4 Correlation coefficient among parameters

\begin{tabular}{lllll}
\hline & $\mathrm{TV}$ & $\mathrm{VC}$ & $\mathrm{RSBI}$ & $\mathrm{PI}_{\mathrm{MAX}}$ \\
\hline Diaphragmatic inspiratory excursion & $0.445^{*}$ & 0.217 & $-0.435^{*}$ & 0.077 \\
TPIA dia $_{\text {d }}$ & $0.639^{*}$ & $0.522^{*}$ & $-0.703^{*}$ & 0.250 \\
DTD & 0.045 & -0.017 & $-0.260^{\pi}$ & 0.166 \\
TFdi & 0.001 & 0.117 & -0.218 & 0.237 \\
\hline
\end{tabular}

$T V$ Tidal volume, $V C$ vital capacity, $R S B I$ rapid shallow breathing index, $P I_{M A X}$ Maximum peak inspiratory pressure, $T P I A_{\text {dia }}$ time to peak inspiratory amplitude, DTD diaphragmatic thickness difference, TFdi diaphragm thickening fraction

${ }^{*} P$ value $<0.01$

${ }^{m} P$ value $<0.05$

TFdi, TV, VC, and $\mathrm{PI}_{\mathrm{MAX}}$ for predicting diaphragmatic dysfunction were $0.720,0.722,0.697,0.762,0.700$, 0.570 , and 0.653 , respectively.

The parameters that predicted reintubation during admission were $\mathrm{PI}_{\mathrm{MAX}}$, RSBI, VC, and TPIA $\mathrm{dia}_{\text {. }}$ The areas under the ROC curves were $0.725,0.652,0.735$, and 0.710 , respectively.

The intra-operator reproducibility analysis of TPIA in the two operators showed an intraclass correlation coefficient of 0.97 (95\% confidence interval, $0.90-0.99 ; P$ $<0.001$ ) and 0.92 (95\% confidence interval, 0.70-0.98; P $<0.001)$, respectively. The inter-operator variability analysis between the two operators revealed a Pearson correlation coefficient ${ }^{\circ}$ of $0.95(\mathrm{P}<0.001)$. The remaining parameters were analyzed as shown in Additional file 1: Table S1.

\section{Discussion}

Ultrasonography provides some advantages as a noninvasive diagnostic tool in critically ill patients, including availability at the bedside and avoidance of radiation hazards. The role of ultrasound in the assessment of diaphragm function has been studied [16] with the rationale that the diaphragm plays a crucial role in respiratory muscle endurance. However, data concerning its usefulness as a weaning predictor are limited [16, 17, 21-23]. We investigated the diagnostic performance of diaphragmatic function parameters assessed by ultrasonography to predict the success of weaning from mechanical ventilation.

The main findings of this study can be summarized as follows. 1) The prevalence of ultrasonographic diaphragmatic dysfunction was $31 \%$. 2) The TPIA dia was a parameter that could be used to predict successful weaning from mechanical ventilation and had a strong correlation with the RSBI. 3) With respect to secondary outcomes, the diaphragmatic inspiratory excursion, DTD, and TFdi could predict reintubation within $48 \mathrm{~h}$. 4) There was no difference between the right and left diaphragmatic parameters.

Diaphragmatic dysfunction is a common condition in the ICU and is associated with prolonged weaning from mechanical ventilation and weaning failure [16]. Jiang et al. [23] hypothesized that displacement of the liver/ spleen as measured by ultrasonography can represent movement of the hemidiaphragms. They demonstrated that using a cutoff value of $1.1 \mathrm{~cm}$ can predict successful extubation [23]. Our study showed that the prevalence of diaphragmatic dysfunction in the medical and surgical ICU was $31 \%$, which is in line with that reported by Kim et al. [16], who demonstrated that $29 \%$ of patients hospitalized in the medical ICU developed diaphragmatic dysfunction.

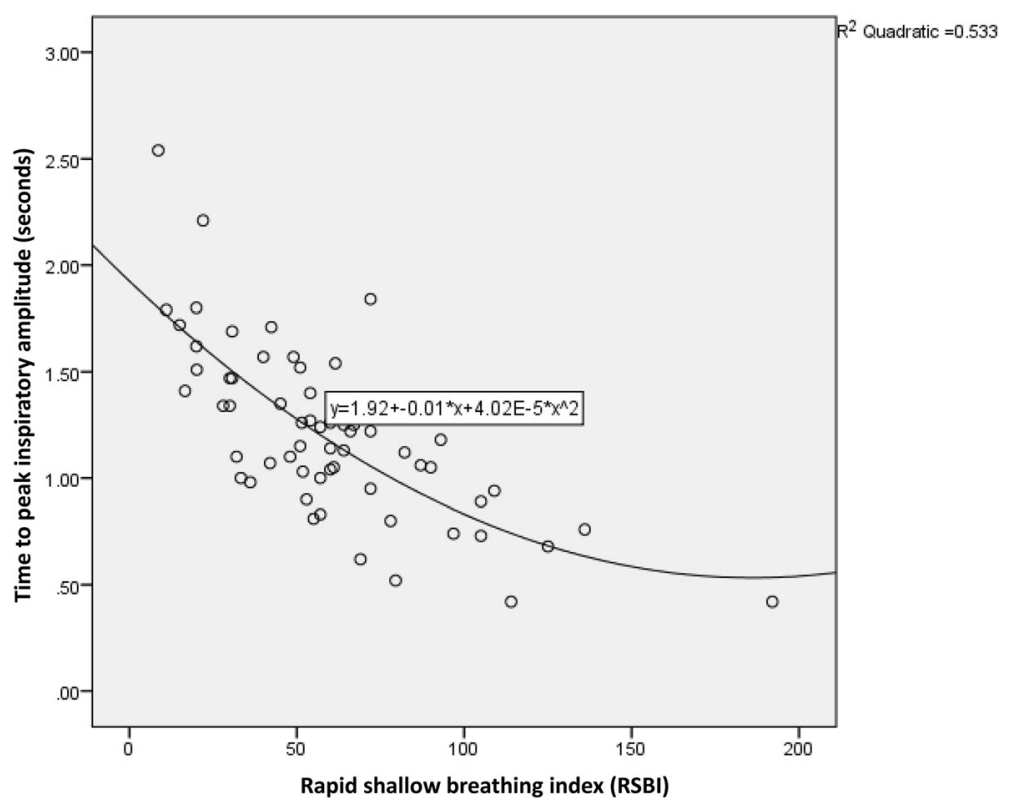

Fig. 4 Relationship between the RSBI and TPIA dia. RSBI, rapid shallow breathing index; TPIA dia, time to peak inspiratory amplitude 
Table 5 Sensitivity, specificity, and negative and positive predictive values of ultrasonography and rapid shallow breathing index for predicting of weaning success

\begin{tabular}{llllll}
\hline Parameters & Sensitivity & Specificity & Positive predictive value & Negative predictive value & Area under the curve \\
\hline TPIA $>0.8 \mathrm{~s}$ & 92.2 & 45.5 & 88.7 & 55.6 & 0.676 \\
$\mathrm{RSBI}<100$ & 96.1 & 45.5 & 89.1 & 71.4 & 0.659 \\
\hline
\end{tabular}

$T P I A_{\text {dia }}$ time to peak inspiratory amplitude, $R S B I$ rapid shallow breathing index

Some previous investigators have performed only right hemidiaphragm ultrasound in the ICU because the acoustic window provided by the liver makes it easier to measure the parameters on this side $[17,21]$. In the present study, we completed both right and left hemidiaphragm measurements without any difficulty. Nevertheless, we found that there was no significant difference between the right and left diaphragmatic parameters (Table 2). Therefore, measurement of the right hemidiaphragm may be more practical in clinical practice.

To the best of our knowledge, this is the first study to compare the performance of various diaphragmatic ultrasound-derived parameters with respect to weaning outcomes in critically ill patients. We also proposed a parameter, the TPIA ${ }_{\text {dia }}$, to predict successful weaning from mechanical ventilation. We found that patients with a longer TPIA dia tended to have more successful weaning from mechanical ventilation, and we found a strong correlation between the TPIA ${ }_{\text {dia }}$ and RSBI. This correlation suggests the presence of a relationship between TPIA $_{\text {dia }}$ and diaphragmatic strength. Physiologically, the strength and endurance of the diaphragm are not similar. Diaphragmatic strength refers to the capacity of the diaphragm to generate force, which is dependent on many factors such as diaphragm contractile activation, excitation-contraction coupling, central drive, nerve conductance, and neuromuscular transmission [24]. Endurance is defined as the ability of the diaphragm to sustain force over time. Our investigation suggests that the TPIA ${ }_{\text {dia }}$ is associated with the strength of the diaphragm rather than its endurance.

In general, a more extended TPIA $\mathrm{Aia}_{\text {in }}$ increases the diaphragmatic amplitude. Therefore, both parameters should display similar results. Although the diaphragmatic inspiratory excursion could predict reintubation, it could not predict weaning success. This result suggests that the diaphragmatic inspiratory excursion represents the endurance of the diaphragm rather than its strength. Why the inspiratory excursion showed a different result from the TPIA ${ }_{\text {dia }}$ is not clear. However, we hypothesize that an individual patient may have his or her own inspiratory time and diaphragmatic amplitude for a required TV. This idea is supported by the relationship between the product of pressure created by respiratory muscle (Pmus) and the electrical activity of the diaphragm (EAdi) measured in neutrally adjusted ventilatory assist mode, as demonstrated in a study by Bellani et al. [25]. The authors showed a different Pmus/EAdi ratio in each patient and indicated that the patients had their own ratios. Consequently, we anticipate different $\mathrm{TPIA}_{\mathrm{dia}} /$ diaphragmatic inspiratory excursion ratios among our patients, and they may have specific ratios of their own. Thus, we found a correlation coefficient of

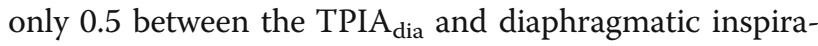
tory excursion in an additional analysis. However, we need to further prove this hypothesis.

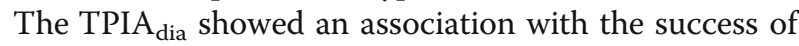
breathing spontaneously without any assisted ventilation, whereas the DTD and TFdi were related to reintubation among the patients in our study. This can be explained by the fact that the DTD represents the endurance of the diaphragm, which is a major factor leading to reintubation. However, we could not explain why the diaphragmatic inspiratory excursion provides a similar result with respect to thickness difference parameters. The transdiaphragmatic pressure-time product needs further determination.

We found no correlation between $\mathrm{PI}_{\mathrm{MAX}}$ and TPIA dia or other diaphragmatic ultrasound parameters. $\mathrm{PI}_{\mathrm{MAX}}$ is

Table 6 a comparison between groups of diaphragmatic dysfunction and non- diaphragmatic dysfunction

\begin{tabular}{|c|c|c|c|c|}
\hline Parameters & Diaphragmatic dysfunction $(n=19)$ & Non-diaphragmatic dysfunction $(n=43)$ & $P$ value & $95 \% \mathrm{Cl}$ \\
\hline $\mathrm{TV}($ mean $\pm \mathrm{SD}, \mathrm{ml})$. & $318.68 \pm 83.46$ & $452.33 \pm 218.34$ & $<0.05$ & 29.87 to 237.41 \\
\hline$V C($ mean $\pm S D, L)$. & $838.89 \pm 263.77$ & $1019.30 \pm 480.77$ & NS & -60.93 to 421.76 \\
\hline $\mathrm{RSBI}$ & $79.53 \pm 40.24$ & $51.67 \pm 25.63$ & $<0.01$ & -44.81 to -10.92 \\
\hline $\mathrm{Pl}_{\mathrm{MAX}}($ mean $\pm \mathrm{SD}, \mathrm{mmHg})$ & $33.72 \pm 11.08$ & $43.63 \pm 17.45$ & $<0.05$ & 0.98 to 18.83 \\
\hline $\mathrm{TPIA}_{\text {dia }}($ mean $\pm \mathrm{SD}$, second $)$ & $0.99 \pm 0.33$ & $1.31 \pm 0.39$ & $<0.01$ & 0.12 to 0.53 \\
\hline DTD (mean \pm SD, mm.) & $0.75 \pm 0.50$ & $1.08 \pm 0.47$ & $<0.05$ & 0.66 to 5.92 \\
\hline TFdi (mean \pm SD,\%) & $25 \pm 12$ & $40 \pm 16$ & $<0.01$ & 6.79 to 23.69 \\
\hline
\end{tabular}

$T V$ Tidal volume, $V C$ vital capacity, $R S B I$ rapid shallow breathing index, $P I_{\text {MAX }}$ Maximum peak inspiratory pressure, $T P I A_{\text {dia }}$ time to peak inspiratory amplitude, $D T D$ diaphragmatic thickness difference, TFdi diaphragm thickening fraction 
a well-known index of respiratory muscle strength. However, some investigators have found that $\mathrm{PI}_{\mathrm{MAX}}$ might be unreliable among patients in the medical ICU [26]. The most objective diagnostic test of respiratory muscle weakness is determination of the transdiaphragmatic pressure in response to phrenic nerve stimulation (PdiTw). Supinski et al. [27] investigated the correlation between PdiTw and $\mathrm{PI}_{\mathrm{MAX}}$. They found that when plotting $\mathrm{PI}_{\mathrm{MAX}}$ against PdiTw, significant scatter was present between the two values, suggesting the unreliability of predicting PdiTw from the determination of $\mathrm{PI}_{\mathrm{MAX}}$. Nevertheless, each value is a predictor of both mortality and the duration of mechanical ventilation. This is in line with our study with respect to the fact that no correlation was found between $\mathrm{PI}_{\mathrm{MAX}}$ and any diaphragmatic ultrasound parameters. The principles of measurement between these parameters are different. The PdiTw is affected by stimulation of the phrenic nerves, and diaphragmatic ultrasound evaluates mainly the diaphragm, whereas $\mathrm{PI}_{\mathrm{MAX}}$ evaluates the inspiratory pressure by the contraction of all inspiratory muscles. Moreover, the diaphragmatic ultrasound examination and measurement of PdiTw were performed during submaximal breathing while measurement of $\mathrm{PI}_{\text {MAX }}$ was performed to assess the highest voluntary inspiratory muscle pressure generation.

Although the areas under the ROC curve of TPIA $_{\text {dia }}$ and the other ultrasound criteria were rather low in our study, they were at least equal to or better than the RSBI, the well-known criteria used in clinical practice. The area under the curve of the ultrasound criteria used to predict the weaning outcome varies from 0.68 to 0.79 among different studies [16, 22]. As evidenced by the quite low area under the curve of these ultrasound criteria indices, weaning failure depends on several clinical factors; for example, it can result not only from diaphragmatic dysfunction or critical illness myopathy but also excess mechanical load, impairment of respiratory mechanics, cardiovascular dysfunction, or an inability to clear secretions. Thus, a single diaphragmatic index might not be a perfect predictor, as shown in a study by Tenza-Lozano et al. [28]. They demonstrated that the area under the ROC curve of TFdi as a single predictor was 0.71 . The performance of TFdi combined with lung ultrasound improved the prediction of weaning success with an AUC of 0.83, which supports our above-mentioned hypothesis [28]. Furthermore, we enrolled many patients of advanced age in the present study. The causes of weaning failure in older patients are multifactorial [29], and few specific parameters are available to predict weaning outcomes in this population [30]. Therefore, diaphragmatic parameters should be combined with other parameters for predicting weaning outcomes.

Since 1991, the RSBI has been used to predict weaning outcomes [19]. It exhibits the best performance compared with the CROP index, $\mathrm{PI}_{\mathrm{MAX}}$, and MV. However, the isolated RSBI may not be precise enough to predict weaning outcomes in patients undergoing prolonged mechanical ventilation [31]. The RSBI is a weaning predictor that measures the change in volume generated by all respiratory muscles while not specifically measuring the diaphragmatic contribution. A study by Kuo et al. [32] showed better performance of the RSBI at the 2-h time point of a spontaneous breathing trial than at the beginning. Consequently, the initial RSBI may not allow for proper assessment of patients with impaired diaphragmatic endurance but may be appropriate for assessment of impaired diaphragmatic strength. We did not find that the RSBI was associated with reintubation within $48 \mathrm{~h}$ after extubation in the present study.

Our study has some limitations. We enrolled both medical and postoperative patients in this study. Therefore, we cannot apply the results to specific diseases, such as chronic obstructive pulmonary disease. Further studies should be conducted to evaluate the role of TPIA $_{\text {dia }}$ in specific diseases. TPIA dia $_{\text {p }}$ provided good sensitivity but low specificity for predicting successful weaning from mechanical ventilation, which means that there were some false-positives at low TPIA ${ }_{\text {dia }}$ values. In other words, a given patient with a TPIA dia $_{\text {of }} \leq 0.8 \mathrm{~s}$ could still have weaning success with an NPV of 56 . However, a positive result that predicts weaning failure does not mean that the patient would have delayed weaning, but should be carefully evaluated during the weaning and extubation periods. Therefore, $\mathrm{TPIA}_{\mathrm{dia}}$ should be interpreted with caution and should be combined with other parameters. A validation cohort study should be conducted to confirm the results of our study. Furthermore, we analyzed the predictors of reintubation during hospital admission, and several uncontrolled variables could have interfered with the outcome (e.g., amount of secretion, consciousness level, or deterioration of the hemodynamic status).

\section{Conclusions}

Among diaphragmatic parameters, the TPIA ${ }_{\text {dia }}$ exhibited good performance in predicting weaning outcomes and had a strong correlation with the RSBI. This study demonstrated a trend toward focusing on the TPIA $_{\text {dia }}$, rather than diaphragmatic inspiratory excursion, as a predictor of weaning from mechanical ventilation.

\section{Additional file}

Additional file 1: Table S1. Inter-operator variability and intra-operator reproducibility of diaphragmatic ultrasound parameters. *Analyzed by intraclass correlation and presented as intraclass correlation coefficient. **Analyzed by Pearson's correlation and presented as correlation coefficient ${ }^{\circledR}$. All parameters exhibited a significant correlation $(P<0.001)$. TPIA dia; Time to peak inspiratory amplitude of diaphragm, DT; diaphragmatic thickness. (DOCX 13 kb) 


\section{Abbreviations}

DT: Diaphragmatic thickness; DTD: Diaphragmatic thickness difference; ICU: Intensive care unit; MV: Minute ventilation; NPV: Negative predictive value; PdiTw: Transdiaphragmatic pressure in response to phrenic nerve stimulation; $\mathrm{PI}_{\text {MAX: }}$ : Maximum peak inspiratory pressure; PPV: Positive predictive value; ROC: Receiver operating characteristic; RSBI: Rapid shallow breathing index; TFdi: Diaphragm thickening fraction; TPIA dia: Time to peak inspiratory amplitude of diaphragm; TV: Tidal volume; VC: Vital capacity

\section{Acknowledgments}

We would like to express our gratitude to all involved internal medicine residents, pulmonary and critical care fellows, and pulmonary and critical care staff members and nurses for their contribution to this project. We also thank Angela Morben, DVM, ELS from Edanz Group (www.edanzediting.com/ac) for editing a draft of this manuscript.

\section{Funding}

Not applicable.

\section{Availability of data and materials}

The datasets used and/or analyzed during the current study are available from the corresponding author on reasonable request.

\section{Authors' contributions}

PT, DE, YS contributed to the study concept, design, planning, data acquisition, analyses, and manuscript preparation. PT, DE, YS and TS contributed to data acquisition and analysis, and interpretation of the data. PT, DE, YS, TS, CK, SK critically reviewed and revised the manuscript for important intellectual content. All authors reviewed the final version of the manuscript prior to submission and all accept responsibility for the integrity of the research process and findings. All authors read and approved the final manuscript.

\section{Ethics approval and consent to participate}

The study was approved by the Ethical Clearance Committee on Human Rights Related to Research Involving Human Subjects, Faculty of Medicine Ramathibodi Hospital, Mahidol University (No. MURA2013/414/N $\mathrm{N}_{3} \mathrm{SP}_{17}$ ). All participants provided written informed consent prior to enrollment. When the patient was unable to provide consent because of consciousness disturbance, the next of kin provided written informed consent.

\section{Consent for publication}

Not applicable.

\section{Competing interests}

The authors declare that they have no competing interests.

\section{Publisher's Note}

Springer Nature remains neutral with regard to jurisdictional claims in published maps and institutional affiliations.

\section{Author details}

${ }^{1}$ Division of Critical Care Medicine, Department of Medicine, Faculty of Medicine Ramathibodi Hospital, Mahidol University, Bangkok, Thailand. ${ }^{2}$ Division of Pulmonary and Pulmonary Critical Care Medicine, Department of Medicine, Faculty of Medicine Ramathibodi Hospital, Mahidol University, Bangkok, 270 Rama 6 Road, Thung Phaya Thai, Ratchathewi, Bangkok 10400, Thailand. ${ }^{3}$ Department of Diagnostic and Therapeutic Radiology, Faculty of Medicine Ramathibodi Hospital, Mahidol University, Bangkok, Thailand.

Received: 23 January 2018 Accepted: 12 November 2018 Published online: 23 November 2018

\section{References}

1. de Letter MA, Schmitz PI, Visser LH, Verheul FA, Schellens RL, Op de Coul DA, et al. Risk factors for the development of polyneuropathy and myopathy in critically ill patients. Crit Care Med. 2001;29:2281-6.

2. Coakley JH, Nagendran K, Yarwood GD, Honavar M, Hinds CJ. Patterns of neurophysiological abnormality in prolonged critical illness. Intensive Care Med. 1998;24:801-7.
3. Coakley JH, Nagendran K, Honavar M, Hinds CJ. Preliminary observations on the neuromuscular abnormalities in patients with organ failure and sepsis. Intensive Care Med. 1993;19:323-8.

4. Berek K, Margreiter J, Willeit J, Berek A, Schmutzhard E, Mutz NJ, Polyneuropathies in critically ill patients: a prospective evaluation. Intensive Care Med. 1996;22:849-55.

5. Leijten FS, De Weerd AW, Poortvliet DC, De Ridder VA, Ulrich C, Harink-De Weerd JE. Critical illness polyneuropathy in multiple organ dysfunction syndrome and weaning from the ventilator. Intensive Care Med. 1996;22:856-61.

6. Chawla J, Gruener G. Management of critical illness polyneuropathy and myopathy. Neurol Clin. 2010;28:961-77.

7. Jaber S, Petrof BJ, Jung B, Chanques G, Berthet JP, Rabuel C, et al. Rapidly progressive diaphragmatic weakness and injury during mechanical ventilation in humans. Am J Respir Crit Care Med. 2011;183:364-71.

8. Levine S, Nguyen T, Taylor N, Friscia ME, Budak MT, Rothenberg P, et al. Rapid disuse atrophy of diaphragm fibers in mechanically ventilated humans. N Engl J Med. 2008;358:1327-35.

9. Hooijman PE, Beishuizen A, Witt CC, de Waard MC, Girbes AR, Spoelstra-de Man AM, et al. Diaphragm muscle fiber weakness and ubiquitin-proteasome activation in critically ill patients. Am J Respir Crit Care Med. 2015;191:112638.

10. Nemer SN, Barbas CS, Caldeira JB, Carias TC, Santos RG, Almeida LC, et al. A new integrative weaning index of discontinuation from mechanical ventilation. Crit Care. 2009;13:R152.

11. Kocis KC, Radell PJ, Sternberger WI, Benson JE, Traystman RJ, Nichols DG. Ultrasound evaluation of piglet diaphragm function before and after fatigue. J Appl Physiol (1985). 1997:83:1654-9.

12. Vivier E, Mekontso Dessap A, Dimassi S, Vargas F, Lyazidi A, Thille AW, et al. Diaphragm ultrasonography to estimate the work of breathing during noninvasive ventilation. Intensive Care Med. 2012;38:796-803.

13. Gottesman E, McCool FD. Ultrasound evaluation of the paralyzed diaphragm. Am J Respir Crit Care Med. 1997;155:1570-4.

14. Lloyd T, Tang YM, Benson MD, King S. Diaphragmatic paralysis: the use of M mode ultrasound for diagnosis in adults. Spinal Cord. 2006;44:505-8.

15. Matamis D, Soilemezi E, Tsagourias M, Akoumianaki E, Dimassi S, Boroli F, et al. Sonographic evaluation of the diaphragm in critically ill patients. Technique and clinical applications. Intensive Care Med. 2013;39:801-10.

16. Kim WY, Suh HJ, Hong SB, Koh Y, Lim CM. Diaphragm dysfunction assessed by ultrasonography: influence on weaning from mechanical ventilation. Crit Care Med. 2011:39:2627-30.

17. DiNino E, Gartman EJ, Sethi JM, McCool FD. Diaphragm ultrasound as a predictor of successful extubation from mechanical ventilation. Thorax. 2014;69:423-7

18. Spadaro S, Grasso S, Mauri T, Dalla Corte F, Alvisi V, Ragazzi R, et al. Can diaphragmatic ultrasonography performed during the T-tube trial predict weaning failure? The role of diaphragmatic rapid shallow breathing index. Crit Care. 2016;20:305

19. Yang $\mathrm{KL}$, Tobin MJ. A prospective study of indexes predicting the outcome of trials of weaning from mechanical ventilation. N Engl J Med. 1991;324: 1445-50.

20. Pasero D, Koeltz A, Placido R, Fontes Lima M, Haun O, Rienzo M, et al. Improving ultrasonic measurement of diaphragmatic excursion after cardiac surgery using the anatomical M-mode: a randomized crossover study. Intensive Care Med. 2015;41:650-6.

21. Ferrari G, De Filippi G, Elia F, Panero F, Volpicelli G, Apra F. Diaphragm ultrasound as a new index of discontinuation from mechanical ventilation. Crit Ultrasound J. 2014:6:8

22. Zambon M, Greco M, Bocchino S, Cabrini L, Beccaria PF, Zangrillo A. Assessment of diaphragmatic dysfunction in the critically ill patient with ultrasound: a systematic review. Intensive Care Med. 2017;43:29-38.

23. Jiang JR, Tsai TH, Jerng JS, Yu CJ, Wu HD, Yang PC. Ultrasonographic evaluation of liver/spleen movements and extubation outcome. Chest. 2004;126:179-85.

24. Ottenheijm CA, Heunks LM, Dekhuiizen RP. Diaphragm adaptations in patients with COPD. Respir Res. 2008;9:12.

25. Bellani G, Mauri T, Coppadoro A, Grasselli G, Patroniti N, Spadaro S, et al. Estimation of patient's inspiratory effort from the electrical activity of the diaphragm. Crit Care Med. 2013;41:1483-91.

26. Multz AS, Aldrich TK, Prezant DJ, Karpel JP, Hendler JM. Maximal inspiratory pressure is not a reliable test of inspiratory muscle strength in mechanically ventilated patients. Am Rev Respir Dis. 1990;142:529-32. 
27. Supinski GS, Westgate P, Callahan LA. Correlation of maximal inspiratory pressure to transdiaphragmatic twitch pressure in intensive care unit patients. Crit Care. 2016;20:77.

28. Tenza-Lozano E, Llamas-Alvarez A, Jaimez-Navarro E, Fernandez-Sanchez J. Lung and diaphragm ultrasound as predictors of success in weaning from mechanical ventilation. Crit Ultrasound J. 2018;10:12.

29. Fujii M, Iwakami S, Takagi H, Itoigawa Y, Ichikawa M, Iwakami N, et al. Factors influencing weaning from mechanical ventilation in elderly patients with severe pneumonia. Geriatr Gerontol Int. 2012;12:277-83.

30. Azeredo LM, Nemer SN, Barbas CS, Caldeira JB, Noe R, Guimaraes BL, et al. The integrative weaning index in elderly ICU subjects. Respir Care. 2017;62: 333-9.

31. Verceles AC, Diaz-Abad M, Geiger-Brown J, Scharf SM. Testing the prognostic value of the rapid shallow breathing index in predicting successful weaning in patients requiring prolonged mechanical ventilation Heart Lung. 2012;41:546-52.

32. Kuo PH, Wu HD, Lu BY, Chen MT, Kuo SH, Yang PC. Predictive value of rapid shallow breathing index measured at initiation and termination of a 2-hour spontaneous breathing trial for weaning outcome in ICU patients. J Formos Med Assoc. 2006:105:390-8.

Ready to submit your research? Choose BMC and benefit from:

- fast, convenient online submission

- thorough peer review by experienced researchers in your field

- rapid publication on acceptance

- support for research data, including large and complex data types

- gold Open Access which fosters wider collaboration and increased citations

- maximum visibility for your research: over $100 \mathrm{M}$ website views per year

At BMC, research is always in progress.

Learn more biomedcentral.com/submissions 